\title{
Model-based analysis of the uptake of perfluoroalkyl acids (PFAAs) from soil into plants
}

\section{Gredelj, Andrea; Polesel, Fabio; Trapp, Stefan}

\section{Published in:}

Chemosphere

Link to article, DOI:

10.1016/j.chemosphere.2019.125534

Publication date:

2020

Document Version

Peer reviewed version

Link back to DTU Orbit

Citation (APA):

Gredelj, A., Polesel, F., \& Trapp, S. (2020). Model-based analysis of the uptake of perfluoroalkyl acids (PFAAs) from soil into plants. Chemosphere, 244, [125534]. https://doi.org/10.1016/j.chemosphere.2019.125534

\section{General rights}

Copyright and moral rights for the publications made accessible in the public portal are retained by the authors and/or other copyright owners and it is a condition of accessing publications that users recognise and abide by the legal requirements associated with these rights.

- Users may download and print one copy of any publication from the public portal for the purpose of private study or research.

- You may not further distribute the material or use it for any profit-making activity or commercial gain

- You may freely distribute the URL identifying the publication in the public portal 


\section{Journal Pre-proof}

Model-based analysis of the uptake of perfluoroalkyl acids (PFAAs) from soil into plants

Andrea Gredelj, Fabio Polesel, Stefan Trapp

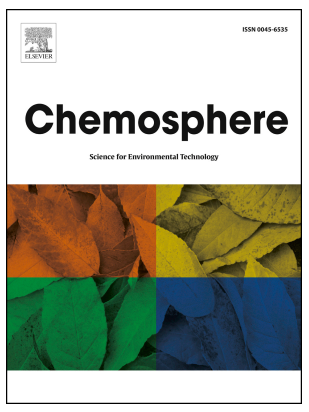

PII:

S0045-6535(19)32774-2

DOI: https://doi.org/10.1016/j.chemosphere.2019.125534

Reference: CHEM 125534

To appear in: ECSN

Received Date: 29 August 2019

Revised Date: 27 November 2019

Accepted Date: 1 December 2019

Please cite this article as: Gredelj, A., Polesel, F., Trapp, S., Model-based analysis of the uptake of perfluoroalkyl acids (PFAAs) from soil into plants, Chemosphere (2020), doi: https://doi.org/10.1016/ j.chemosphere.2019.125534.

This is a PDF file of an article that has undergone enhancements after acceptance, such as the addition of a cover page and metadata, and formatting for readability, but it is not yet the definitive version of record. This version will undergo additional copyediting, typesetting and review before it is published in its final form, but we are providing this version to give early visibility of the article. Please note that, during the production process, errors may be discovered which could affect the content, and all legal disclaimers that apply to the journal pertain.

(C) 2019 Published by Elsevier Ltd. 


\section{CRediT author statement}

Andrea Gredelj: Conceptualization, Methodology, Formal analysis, Investigation, Writing Original Draft, Visualization

Fabio Polesel: Validation, Writing - Review \& Editing

Stefan Trapp: Methodology, Software, Validation, Resources, Data Curation, Writing - Review \& Editing, Supervision 

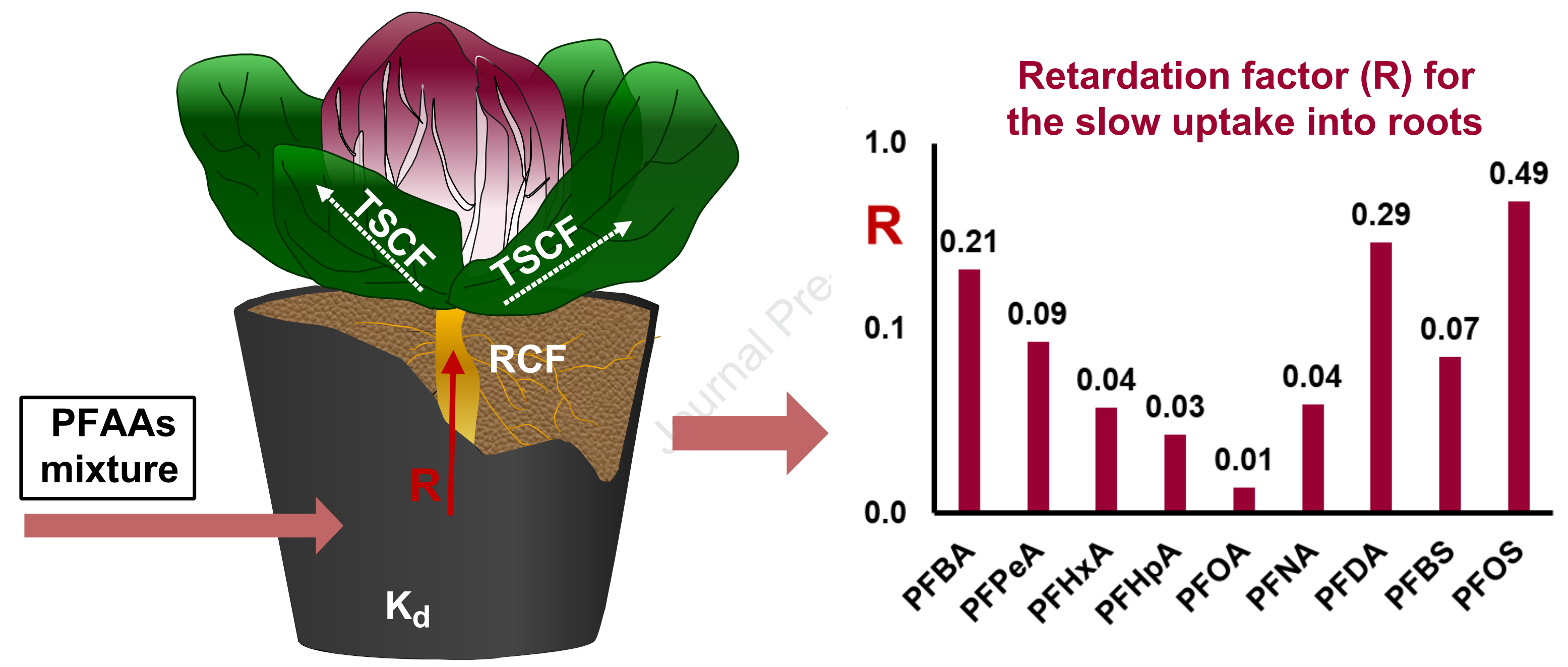
Model-based analysis of the uptake of perfluoroalkyl acids (PFAAs) from soil into plants

2

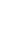

Andrea Gredelj ${ }^{\mathrm{a}, \mathrm{b} *}$, Fabio Polesel ${ }^{\mathrm{a}, \mathrm{c}}$, Stefan Trapp ${ }^{\mathrm{a}}$

${ }^{a}$ Technical University of Denmark, Department of Environmental Engineering, Bygningstorvet 115, DK-2800 Kongens Lyngby, Denmark

${ }^{\mathrm{b}}$ Department of Industrial Engineering, University of Padova, via Marzolo 9, 35131 Padova, Italy ${ }^{c}$ DHI A/S, Agern Allé 5, 2970 Hørsholm, Denmark

* Corresponding author. E-mail address: andrea.gredeli@phd.unipd.it

\section{Abstract}

Perfluoroalkyl acids (PFAAs) bioaccumulate in crops, with uptake being particularly high for short-chain PFAAs that are constantly transported with transpiration water to aerial plant parts. Due to their amphiphilic surfactant nature and ionized state at environmental $\mathrm{pH}$, predicting the partitioning behavior of PFAAs is difficult and subject to considerable uncertainty, making experimental data highly desirable. Here, we applied a plant uptake model that combines advective flux with measured partition coefficients to reproduce the set of empirically derived plant uptake and soil-partitioning data for nine PFAAs in red chicory, in order to improve the mechanistic understanding and provide new insights into the complex uptake processes. We introduced a new parameter for retarded uptake $(R)$ to explain the slow transfer of PFAA across biomembranes of the root epidermis, which have led to low transpiration stream concentration factors (TSCFs) presented in literature so far. We estimated $R$ values for PFAAs using experimental data derived for red chicory and used the modified plant uptake model to simulate uptake of PFAA into other crops. Results show that this semi-empirical model predicted PFAAs transport to shoots and fruits with good accuracy based on experimental root to soil concentration factors $\left(R C F_{d w}\right)$ and soil to water partition coefficients $\left(K_{d}\right)$ as well as estimated $R$ 
25 values and plant-specific data for growth and transpiration. It can be concluded that the 26 combination of rather low $K_{d}$ with high $R C F_{d w}$ and the absence of any relevant loss are the 27 reason for the observed excellent plant uptake of PFAAs.

28

29 Keywords: Plant Uptake; PFOS; PFOA; Membrane Permeability; Exposure Assessment; 30 Transpiration

Stream 


\section{Introduction}

Per- and polyfluoroalkyl substances (PFASs) are a family of anthropogenic chemicals containing at least one perfluoroalkyl moiety $\left(-\mathrm{C}_{n} \mathrm{~F}_{2 n}-\right)$. Due to their high stability and surfactant properties of some PFASs, PFASs have been used in a variety of industrial and commercial products and processes since the 1950s (Buck et al., 2011; DeWitt et al., 2018). It is estimated that more than 4000 individual PFASs are currently present on the market (Cheng and $\mathrm{Ng}$, 2018). Wide-range emissions, high thermal and (bio)chemical stability and amphiphilicity determine their persistence and ubiquitous presence in the environment, from tropical to polar areas (Chen et al., 2017; Greaves et al., 2012).

The most commonly detected (and now "historical") PFASs in environment, wildlife and humans are perfluorooctane sulfonic acid (PFOS) and perfluorooctanoic acid (PFOA) (Cheng and Ng, 2018; Krafft and Riess, 2015a). Substances containing a perfluoroalkyl moiety have the potential to be transformed abiotically or biotically through changes in the non-fluorinated part of the molecule into perfluoroalkyl acids (PFAAs), which are regarded as their final stable transformation products (Brendel et al., 2018; Buck et al., 2011; Ghisi et al., 2019). PFAAs are acidic surfactants that, within the group, differ in perfluoroalkyl chain length and in the terminal polar group (consequently forming carboxylic, sulfonic, sulfinic, phosphonic, and phosphinic perfluoroalkyl acids). After their common detection in humans and biota, long-chain perfluorocarboxylic (PFCAs) and perfluorosulfonic (PFSAs) acids (defined as $\geq 7 \mathrm{C}$ for PFCAs, $\geq$ 6C for PFSAs) from C8 to C14 have been voluntarily phased-out by producers and are subject to the subsequent regulation (e.g. PFOS and its salts are restricted under the Stockholm Convention) (Buck et al., 2011). Precursors of short-chain PFAAs are broadly used as their alternatives (Brendel et al., 2018). Long- and short-chain PFAAs were originally distinguished with the assumption that short-chain PFAAs have a lower bioaccumulation potential and are less persistent compared to the long-chain ones (Buck et al., 2011). In animal and human body, 
bioaccumulation was accordingly found to steeply increase with chain length (Krafft and Riess, 2015) and to be higher for PFSAs than PFCAs. However, recent findings have shown the opposite pattern for crops and other plants, whereby short-chain PFCAs are accumulating to a high extent in aerial plant parts (Blaine et al., 2014a; Felizeter et al., 2014; Ghisi et al., 2019). Food of plant origin was identified as an important category contributing to dietary exposure to PFAAs (D’Hollander et al., 2015; Felizeter et al., 2014; Klenow et al., 2013).

PFAAs in the environment are present in anionic form, suggesting weak adsorption to soil (Franco et al., 2009), high water solubility and negligible vapor pressure. This combination of properties, together with their extreme persistence, imposes PFAAs as good candidates for high uptake and accumulation in crops, consequently making the exposure and fate assessment for the soil-plant pathway highly needed. Sorption to soil strongly depends on the soil type and it is not fully ascribable to the soil's organic carbon content (\%OC) (Y. Li et al., 2018) but usually increases with the chain length (Guelfo and Higgins, 2013; McLachlan et al., 2019), with longchain PFAAs adsorbing strongly to soil (McLachlan et al., 2019; Milinovic et al., 2015). Motivated by the contamination event caused by a fluorochemical plant in the Veneto Region, Northern Italy (WHO, 2016), and the significance of the area for the crop production and its extensive irrigation needs (Veneto Region, 2014), a previous study was conducted to measure uptake of 9 PFAAs into red chicory (Cichorium intybus L.) under simulated environmental conditions of contaminated soil and irrigation water (Gredelj et al., 2019). Differently from previous studies on PFAAs uptake in crops (Blaine et al., 2014a, 2014b, 2013; Navarro et al., 2017; Xiang et al., 2018), plant-specific data and sorption to soil and roots were also measured and served as input for the plant uptake model derived here.

A widely used plant uptake model is the so-called "standard model" (Trapp, 2015, 2007; Trapp and Matthies, 1995). It combines advective fluxes into and through the plant with partition processes to roots, stem and leaves with volatilization, degradation and dilution by growth as 
81

82

83

84

85

86

87

88

89

90

91

92

93

94

95

96

97

98

99

100

101

102

103

104

loss processes. Its adaption to weak acids and bases is available as well (Trapp, 2009). This basic approach has been adopted in assessment tools for contaminated soils (CSOIL (Brand et al., 2007); CLEA (Jeffries and Martin, 2009)), in chemical risk assessment (European Commission, 2003) and in sustainability assessment (dynamiCROP (Fantke et al., 2011b, 2011a)). Most, if not all, of these established assessment tools require knowledge of the equilibrium partitioning between environmental compartments, in particular for adsorption to soil $\left(K_{d}\right.$-value) and to plant tissue (root concentration factor $\left.R C F\right)$. Only, the estimation routines for partitioning implemented in these exposure assessment tools are strictly restricted to neutral, nonpolar chemicals (Trapp et al., 2010). PFAAs do not have typical lipid partitioning mechanisms due to their ionic state and surfactant nature, showing low storage lipid accumulation and high affinity for proteins (Cheng and $\mathrm{Ng}, 2018$; Droge, 2019; $\mathrm{Ng}$ and Hungerbühler, 2014) and resulting in great uncertainty of both experimentally and QSAR based Kow-values (Droge, 2019). Therefore, the partition coefficients cannot be estimated from structure or from physico-chemical properties, but need to be determined empirically or by inverse modeling.

In this study, we used experimental soil-water partition coefficients and measured PFAA concentrations in red chicory grown in soil provided by (Gredelj et al., 2019), together with plantspecific input parameters to calibrate the standard plant uptake model for PFAAs. We introduced a new parameter for retarded uptake into roots and xylem, and estimated it for all tested PFAAs. We also evaluated the relationship between the chemical structure (perfluoroalkyl acid's chain length) and root to water, root to soil and water to soil partition coefficients. The model was then applied to other experimental PFAA uptake data presented in literature to validate the modelling approach used. Overall, the outcome of our investigation allows for an improved interpretation of the experimental results and for the comparison of 
105 PFAAs with other chemicals, providing new insights into the uptake mechanisms of PFAAs into

106 crops and being a step forward towards the prediction of the uptake of PFAAs into crops.

\section{Methodology}

\subsection{Perfluoroalkyl acids}

109 Physico-chemical properties of PFAAs differ with the functional group and are decreasing or 110 increasing with the chain length (Smith et al., 2016). A list of the PFAAs used in this study

111 together with their names, structures and relevant physico-chemical properties is shown in 112 Table 1.

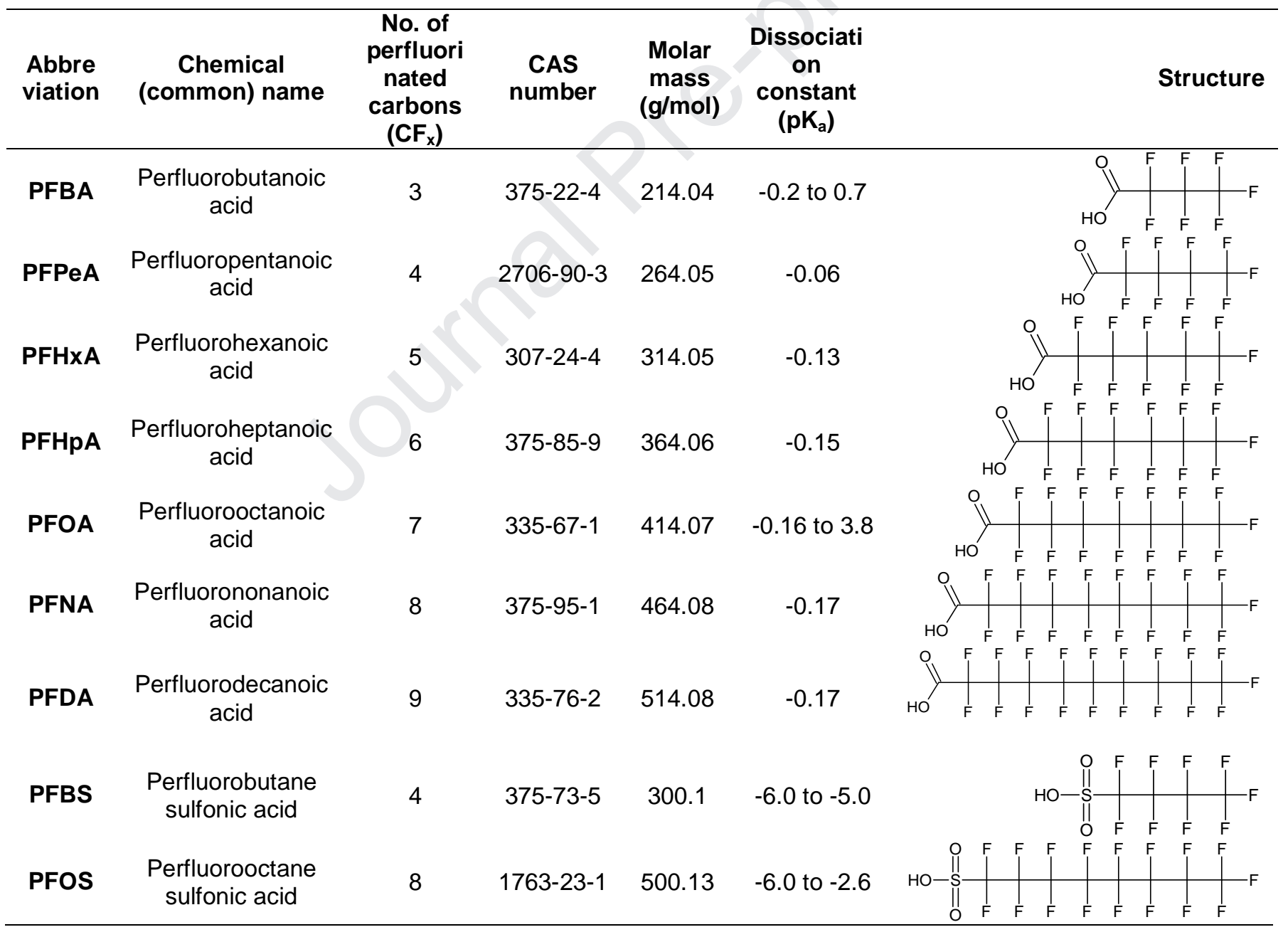

113 Table 1. A list of investigated PFAAs with relevant physico-chemical properties (Smith et al., 2016) 


\subsection{Experimental data}

115 Experimental uptake data for a mixture of nine PFAAs (Table 1) into red chicory plant 116 compartments were taken from the study of (Gredelj et al., 2019). Only the data from experiments with pre-contaminated soil were considered to avoid non-equilibrium conditions resulting from the use of spiked irrigation water (Blaine et al., 2014b). Briefly, uptake experiments with red chicory (Cichorium intybus L.) were performed in a greenhouse located in Legnaro (Italy) from August to November 2018. Plants were grown in pots containing $11 \mathrm{~kg}$ of agricultural soil (loam), spiked to nominal concentrations of $100 \mathrm{ng} / \mathrm{g}_{\mathrm{dw}}$ or $200 \mathrm{ng} / \mathrm{g}_{\mathrm{dw}}$ of each PFAA. Concentrations of PFAAs in soil were analytically determined at the beginning and at the end of experimental period of 87 days, as well as final concentrations in roots, leaves and heads of the red chicory plants.

For determination of transpiration and growth rates, the pots were weighed before every irrigation. This was also done for non-planted controls to determine evaporative losses of water. The gravimetric water content of the soil was measured at the beginning (before planting) and at the end of the experiments. Moreover, plant biomass was measured at the beginning (by weighing the seedlings before planting) and at the end of the experiments for each plant compartment. Dry matter content of plant tissue was determined by oven drying at $65 \mathrm{C}(72 \mathrm{~h})$.

Partitioning of PFAAs between soil and water was determined by a set of batch adsorption/desorption experiments (following the standardized OECD guideline 106 (OECD, 2000)), using concentration ranges relevant for the plant uptake experiments. For the long-chain PFAAs (i.e. PFOA, PFNA, PFDA, PFOS) both adsorption and desorption-based soil-water partition coefficients were derived, $K_{d, \text { ads }}(\mathrm{L} / \mathrm{kg})$ and $K_{d, \text { des }}(\mathrm{L} / \mathrm{kg})$, respectively, only $K_{d, \text { des }}$ being 136 relevant for the used treatments with the pre-contaminated soil. For the other PFAAs, 137 concentrations of PFBA, PFPeA, PFBS and PFHxA in solution could not be quantified precisely enough in the consecutive desorption tests performed with "decant-refill" technique, due to their 
rather low adsorption to soil and their low concentrations in the desorption reactors (Gredelj et al., 2019). However, considering their low $K_{d}$ values and the adsorption reversibility of the shortchain PFAAs (Chen et al., 2016; Milinovic et al., 2015), $K_{d, a d s}$ values were applied in uptake calculations with the short-chain PFAAs.

Data from (Gredelj et al., 2019), including the measured PFAA concentrations in soil and plant compartments and soil-water partition coefficients are listed in the SI (Tables S1 and S4).

\subsection{Model description}

The main purpose of the model application here is the interpretation of measured PFAA uptake data. Chemical model input parameters, specific for the investigated PFAAs, were determined either directly from the experimental data or by model calibration. This enabled us to identify plant-specific factors that influence PFAAs uptake and allowed to transfer from the red chicory experiment to other experimental results, assuming that the chemical-specific parameters remain constant and only the environmental parameters vary.

\subsubsection{Soil}

Earlier plant uptake studies with PFAAs (Bizkarguenaga et al., 2016; Blaine et al., 2014a, 2013; Navarro et al., 2017) provided measured PFAA concentrations in dry soil and bioconcentration factors on a dry weight basis as descriptors for accumulation in plants. Thus, the model was modified to accommodate for dry weight-based root to soil bioconcentration factors $\left(R C F_{d w}\right)$ and PFAA concentration in dry soil $\left(c_{0}\right)$.

The gravimetric water content $w(\mathrm{~g} / \mathrm{g})$ of soil was determined by weighing the wet soil and the soil after drying in the oven at $105^{\circ} \mathrm{C}$ for $72 \mathrm{~h}$ (AS TM International, 2019). The concentration of each PFAA in the pore water $c_{p w}(\mu \mathrm{g} / \mathrm{L})$ of soil is then: 


$$
c_{p w}=\frac{c_{0}}{K_{d}+\frac{w}{\rho_{H_{2} O}}}
$$

161

where $c_{0}$ is the respective concentration in dry soil $\left(\mathrm{ng} / \mathrm{g}_{\mathrm{dw}}\right.$, measured before planting), $K_{d}(\mathrm{~mL} / \mathrm{g})$ is the soil-water distribution coefficient determined in adsorption or desorption experiments, as described, and $\rho_{\text {H2O }}(\mathrm{g} / \mathrm{mL})$ is the density of water. $w$ is defined as ratio of the mass of water contained in soil and mass of dry soil.

Considering $K_{w s}(\mathrm{~g} / \mathrm{mL})$ as the concentration ratio between pore water $c_{p w}$ and bulk (wet) soil concentration $c_{\text {soil }}$ (equal to $c_{0} /(1+w)$ ), the pore water concentration is given as:

$$
c_{p w}=K_{W S} c_{s o i l}=K_{W S} \frac{c_{0}}{1+w}=\frac{c_{0}}{K_{d}+\frac{w}{\rho_{H_{2} O}}}
$$

\subsubsection{Roots and shoots}

PFAAs are non-degradable and present in ionic form at environmental $\mathrm{pH}$. Loss due to plant metabolism, photolysis (or other abiotic degradation processes) and volatilization can thus be safely neglected (Krafft and Riess, 2015; Liu and Avendaño, 2013). Moreover, in the case of red chicory, only the root and shoot compartments (later divided into leaves and head) need to be considered, while stem and fruits can be neglected, simplifying the model to two differential equations describing mass balances for roots and for shoots (leaves and heads), respectively.

The inflow of PFAA from soil pore water and the outflow via xylem lead to the mass balance for roots (Trapp, 2015, 2002):

$$
\frac{d m_{R}}{d t}=R Q c_{p w}-Q c_{X y}
$$

176 where $m_{R}$ is the mass of contaminant in roots $(\mu \mathrm{g}), Q$ is the transpiration stream $(\mathrm{L} / \mathrm{d}), c_{p w}$ is the concentration in pore water $(\mu \mathrm{g} / \mathrm{L})$ and $c_{X y}$ is the concentration in xylem at the outflow of the root 
$178(\mu \mathrm{g} / \mathrm{L}) . R$ is a new factor describing the retardation of uptake relative to water $(R \leq 1$, unitless)

179 (more details are given in the section 2.4.).

180 Equation (3) can be modified:

181

182

183

184

185

186

187

The differential equation for the change of concentration in roots therefore becomes:

$$
\frac{d c_{R}}{d t}=R \frac{Q}{M_{R}} K_{W S} c_{s o i l}-\frac{Q}{M_{R} K_{R X}} c_{R}-k_{R} c_{R}
$$

188

The steady-state solution of this differential equation is:

$$
c_{R}=\frac{\frac{R Q}{M_{R}}}{\frac{Q}{K_{R X} M_{R}}+k_{R}} K_{W S} c_{\text {soil }}
$$

Accordingly, the change of concentration in shoots due to the inflow from roots and with 190 exponential growth dilution is:

$$
\frac{d c_{S}}{d t}=\frac{Q}{M_{S} K_{R X}} c_{R}-k_{S} c_{S}
$$

191 where $c_{S}$ is the concentration of contaminant in shoots $\left(\mu \mathrm{g} / \mathrm{kg}_{\mathrm{fw}}\right), c_{R}$ is the steady-state 192 concentration in roots $\left(\mu \mathrm{g} / \mathrm{kg}_{\mathrm{fw}}\right), k_{s}$ is the growth rate of the shoots $(1 / \mathrm{d})$ and $M_{S}$ their mass $193\left(\mathrm{~kg}_{\mathrm{fw}}\right)$. The differential equation (6) was solved analytically for $\mathrm{t}=87$ days. The reader is referred 194 to (Legind and Trapp, 2009; Trapp, 2009, 2007), where more detailed numerical and visual 195 descriptions of the model are provided. 
196

197

198

199

200

201

202

203

204

205

206

207

208

209

210

211

212

213

214 adsorbed):

$$
R C F_{d w}=\frac{P F A A \text { concentration in roots }\left(n g / g_{d w}\right)}{P F A A \text { concentration in soil }\left(n g / g_{d w}\right)}
$$

215 The retardation factor $\boldsymbol{R}$ has been introduced to interpret the observed values of the 216

\subsection{Model calibration}

According to the equations of the standard plant uptake model, all of the chemical that is taken up into the roots partitions between root tissue and xylem water. The latter fraction is translocated upwards. The chemical reaching the shoots accumulates there, as no relevant loss processes occur for PFAAs. Thus, the equation system contains only two chemical-specific parameters, namely:

The partition coefficient $K_{R X}$ is describing the equilibrium concentration ratio of the chemical between root tissue and water in the xylem. Xylem solution consists of water, and for neutral compounds, $K_{R X}$ is identical to the partition coefficient between roots and water $K_{R W}$ (also known as root concentration factor RCF) which can be estimated from the Kow (Briggs et al., 1982). For partly ionized substances, additional effects like the ion trap need to be considered (Briggs et al., 1987; Trapp, 2009). For purely ionic substances (like PFAAs), no reliable estimation method has been provided so far. By considering root water content $w_{R}$ and soil-water partition coefficient $K_{d}$ (either adsorption or desorption based) it follows that the fresh-weight based partition coefficient $K_{R X}\left(\mathrm{~L} / \mathrm{kg}_{\mathrm{fw}}\right)$ can be calculated as:

$$
K_{R X}=R C F_{d w}\left(1-w_{R}\right)\left(K_{d}+\frac{w}{\rho_{H 2 O}}\right)
$$

where $w_{R}$ is the water content of fresh roots, $R C F_{d w}$ is the empirical root concentration factor, calculated as the ratio between measured root concentration of PFAA and total measured concentration in soil (accounting for all PFAA present in soil, not only the fraction that is transpiration stream concentration factor (TSCF), defined as the concentration ratio between 
xylem sap and soil pore water (Trapp and Matthies, 1995). Parameter $R$ describes the uptake

218 velocity of a chemical relative to the water and is thus comparable to the plant uptake factor 219 PUF (Gourlay, 2017; Lamshoeft et al., 2018). The underlying mechanism is the difference 220 between root permeability for a chemical and water, so $R$ can be defined as the ratio:

$$
R=\frac{P_{R, \text { Chem }}}{P_{R, H_{2}} \mathrm{O}}
$$

221 with $R \leq 1$ (advective uptake is never faster than the flow with water), where $P_{R, C h e m}(\mathrm{~m} / \mathrm{s})$ and $222 P_{R, H 2 O}(\mathrm{~m} / \mathrm{s})$ are the root membrane permeabilities towards chemical and water, respectively. 223 For very polar chemicals (usually ionic, PFAAs included), uptake into the root is slower than that 224 of water, while for other chemicals $R$ equals 1 . The effect of $R<1$ is a slower uptake and thus a lower TSCF. For example, measured water permeabilities of barley roots ranged from 0.4 to 6 $\times 10^{-9} \mathrm{~m} / \mathrm{s}$ (Steudle and Peterson, 1998). The membrane permeability for neutral compounds can be estimated with satisfying accuracy from $K_{\text {Ow }}$ (Trapp, 2004):

$$
\log P_{R, \text { Chem }}=\log K_{O W}-6.7
$$

228

which means that only chemicals with $\log K_{\text {ow }}$ less than about $-2(\log L / L)$ would have a membrane permeability slower than water and consequently $R<1$. For purely ionic substances like PFAAs, such estimates are unreliable.

The TSCF (L/L) can be calculated from established empirical equations, but being also based on the $K_{\text {ow, }}$ their applicability is restricted to neutral compounds (Briggs et al., 1982; Dettenmaier et al., 2009). Instead, TSCF can be found from the measured data as:

$$
\operatorname{TSCF}=\frac{m_{s}}{c_{p w} \sum(Q t)}
$$

where $m_{s}(\mu \mathrm{g})$ is the mass of chemical in shoots at the harvest, $\Sigma(Q t)(L)$ is the total volume of the water transpired during the growth period (until the harvest) and $c_{p w}(\mu \mathrm{g} / \mathrm{L})$ is the 
Principally, the TSCF can also be calculated with the root model equation (Trapp, 2007):

$$
T S C F=\frac{c_{X y}}{c_{p w}}=\frac{R Q}{Q+K_{R X} k_{R} M_{R}}
$$

Vice versa, if the TSCF has been measured, the retardation factor can be calculated from TSCF 243 (as was done here):

$$
R=\operatorname{TSCF}\left(1+\frac{K_{R X}}{Q} k_{R} M_{R}\right)
$$
each with 5 planted pots and one empty pot that included only soil and no plant (Gredelj et al., 254

\subsection{Plant parameters and model parametrization}

Plant-specific parameters can have a very significant impact on the uptake of chemicals into plants (Trapp, 2015). In the present study, transpiration and growth rates, together with water contents of the soil and crops were measured, providing the site-specific data set for fitting the measured PFAA concentrations in crop compartments and soil. The average transpiration coefficient (volume of water transpired per mass of the plant weight) was $35.2 \mathrm{~L} / \mathrm{kg}_{\mathrm{fw}}$. From the measured data, average daily transpiration rate and growth rates were calculated (Text S1) and the input parameters are shown in Table S2. All data were calculated and fitted to individual plants (pots) and the results are shown as average per each treatment (initially 12 treatments, 2019)). As the shoot concentrations (calculated from the measured concentrations and masses 
255

256

of heads and leaves) were used for calculation of $R$ values, model performance was tested for the chicory leaves and heads separately by using the determined plant specific data listed in Table S2.

\subsection{Applying the modeling approach to other crops}

In order to test the semi-empirical model calibrated for PFAAs uptake into red chicory, the model and the calibrated values of $R$ were used to estimate concentrations in roots, shoots and fruits of tomato, celery, pea and radish plants. In the respective studies, soil-water partition coefficient $K_{d}$ and compartmental concentrations of the same set of PFAAs were determined (Blaine et al., 2013; Blaine et al., 2014a), but no plant specific input data except time to harvest and water content of plant material were available. Accordingly, for these experimental results, model calculations were made with the default plant dataset listed in (Trapp, 2015). To evaluate the significance of using the plant specific data (Table S5), red chicory uptake was additionally simulated with the default parameters and compared to simulations with chicory-specific plant data.

\subsection{Statistical evaluation of the results}

The performance of model calculations was evaluated by the means of least-squares linear regression between predicted and measured concentration values in the different plant compartments for all PFAAs. With axis intercept forced to zero, the slope is a measure of the accuracy of the model simulations, while $R^{2}$ is a measure of the calculations precision. All statistical analyses were performed using the Data Analysis ToolPak from MS Excel@ add-in.

\section{Results and discussion}

\subsection{Modeling results and measurements}

Figure 1 shows measured and calculated concentrations of PFAAs in leaves and heads of red chicory, based on chicory-specific plant data and the nominal exposure concentrations of 100 
and $200 \mathrm{ng} / \mathrm{g}_{\mathrm{dw}}$ (namely, from (Gredelj et al., 2019), treatments S100W0 and S200W0). Data are shown from the lowest to the highest perfluoroalkyl chain length, including both PFCAs and PFSAs. For both heads and leaves, the model expectedly reproduced the trend of PFAAs distribution in leaves and heads $\left(R^{2}\right.$-values of the regression lines between modeled and measured values being $>0.92$, Table S8), always overestimating concentrations for leaves (slopes of the regression line were 1.26 and 1.32 for S100W0 and S200W0, respectively, Table S8). Overestimated modeled concentrations could be the consequence of the oldest leaves that withered and were, therefore, not extracted and analyzed. They transpired for the longest period and probably had higher concentrations (than those actually measured in the remaining leaves) of accumulated PFAAs, as stated in (Gredelj et al., 2019). The model performed generally better for the treatment S100W0 and performance was better for PFCAs than PFSAs (estimation statistics improved after neglecting PFBS and PFOS from regression of modeled and measured concentrations, Table S8).
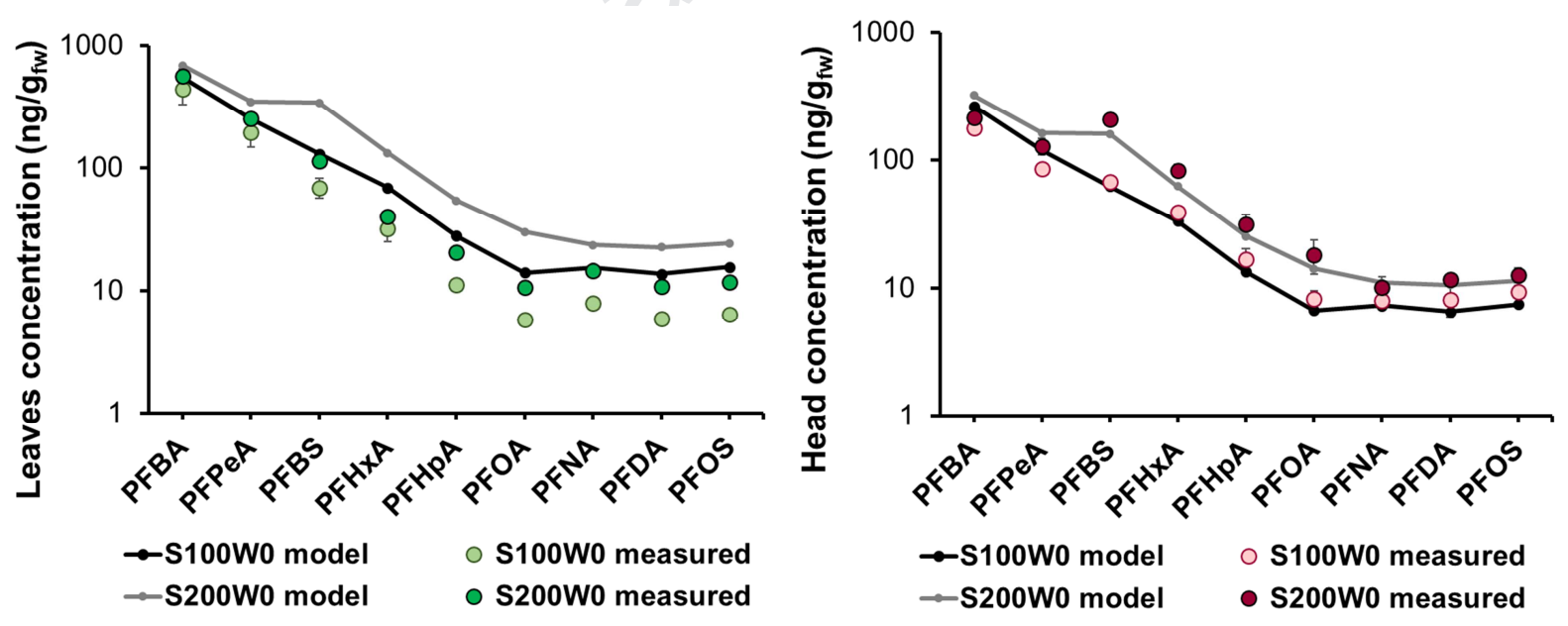
head for two exposure concentrations. Estimated standard errors are shown for the measured data. Measured values are taken from (Gredelj et al., 2019).

\section{2. $R$ values}


Figure 2 shows the estimated $R$ values for the two exposure concentrations used in the experiments. Values of $R$ for PFCAs decline with chain length, from $3 \mathrm{CF}_{\mathrm{x}}$ to $7 \mathrm{CF}_{\mathrm{x}}$, but increase from $7 \mathrm{CF}_{\mathrm{x}}$ to $9 \mathrm{CF}_{\mathrm{x}}$, in an almost log-linear pattern.

Due to the relatively low $K_{R x}$-values, the numerical values of $R$ are close to the values of the TSCF (Table 3). Except for PFOS, PFDA and PFBA, all PFAA have TSCF and $R$-values smaller than 0.1. Similarly, (Briggs et al., 1987) found TSCF-values of weak acids with $p K_{a}$ about 3 ( $p K_{a}$ 2.84 to 3.7 ) at $\mathrm{pH} 7$ (thus, about $99.99 \%$ ionized) rather constant at 0.02 to $0.05 \mathrm{~L} / \mathrm{L}$, median $0.04 \mathrm{~L} / \mathrm{L}$. This is close to the lower $R$ values observed here, obtained for the short-chain PFAAs (except PFBA), which were between 0.01 and 0.09 .

\begin{tabular}{lrrrrrr}
\hline \multirow{2}{*}{ PFAA } & \multicolumn{2}{c}{$\mathrm{K}_{\mathrm{RX}}(\mathrm{L} / \mathrm{kg})$} & \multicolumn{2}{c}{ TSCF $(\mathrm{L} / \mathrm{L})$} & \multicolumn{2}{c}{$\mathrm{K}_{\mathrm{RX}} / \mathrm{TSCF}(\mathrm{L} / \mathrm{kg})$} \\
& S100W0 & S200W0 & S100W0 & S200W0 & S100W0 & S200W0 \\
\hline PFBA & 13.7 & 20.7 & 0.22 & 0.18 & 62.0 & 116.1 \\
PFPeA & 4.18 & 7.27 & 0.09 & 0.08 & 47.5 & 90.8 \\
PFBS & 5.16 & 7.42 & 0.06 & 0.08 & 81.1 & 98.7 \\
PFHXA & 3.15 & 3.97 & 0.04 & 0.04 & 88.7 & 102.2 \\
PFHpA & 2.28 & 2.78 & 0.02 & 0.03 & 95.1 & 94.4 \\
PFOA & 1.25 & 1.40 & 0.01 & 0.01 & 93.1 & 98.1 \\
PFNA & 3.47 & 2.47 & 0.04 & 0.04 & 82.3 & 70.4 \\
PFDA & 26.6 & 17.5 & 0.29 & 0.26 & 90.5 & 68.3 \\
PFOS & 50.2 & 28.7 & 0.54 & 0.34 & 93.6 & 84.5 \\
\hline
\end{tabular}

Table 2. Calculated values of the root-xylem partition coefficient $\left(K_{R X}\right)$, transpiration stream concentration factor (TSCF) and their ratio $\left(K_{R X} / T S C F\right)$ for all modeled PFAAs

Trends for PFAA accumulation in shoots and roots were similar (increasing from $3 \mathrm{CF}_{\mathrm{x}}$ to $9 \mathrm{CF}_{\mathrm{x}}$ of PFCAs) (Gredelj et al., 2019), implying that PFAAs substantially entering the roots (and having the highest $R C F_{d w}$ ) will also be transferred into shoots with transpiration water. Conversely, residual mass accumulated in the root cortex or the apparent free space cannot be translocated upwards and could have been lost before extraction (as explained in Gredelj et al., (2019)), considering the conclusions of (Felizeter et al., 2012) that the longest PFAAs adsorb externally to root surfaces of the lettuce grown in a hydroponic system. In addition to our 
315 hypothesis, the ratio of $K_{\mathrm{RX}} / T S C F$ is almost constant, usually not being the case for other 316 chemicals. When the TSCF had been calculated from the original root model (Trapp, 2007) it 317 gave a sigmoid curve, similarly to what had been observed by (Dettenmaier et al., 2009), with 318 highest TSCF values for polar compounds (low $K_{R X}$ ), while low TSCF values had been 319 calculated for strongly adsorbing lipophilic compounds (high $K_{R x}$ ) (Trapp, 2007). In other words, 320 there was an inverse relation between adsorption to roots and translocation to shoots for 321 neutral, lipophilic compounds. The low TSCF-values found here for PFAAs, therefore, are not 322 originating from the adsorption to root tissue and retention within the main root, but due to their 323 deceleration in the epidermal cell membranes, here described by the new factor $R$. The 324 increase in $R$, observed with chain length increase above $7 C_{\mathrm{x}}$, may be a consequence of the 325 pronounced surfactant nature of these PFAAs. They could have formed a film around the root 326 cell membranes and either resided in the apparent free space (up to $40 \%$ of the root volume) 327 (Mc Farlane and Trapp, 1994) or on the membrane surfaces, a possibility even when the cell 328 interior is accessible for PFAAs. 

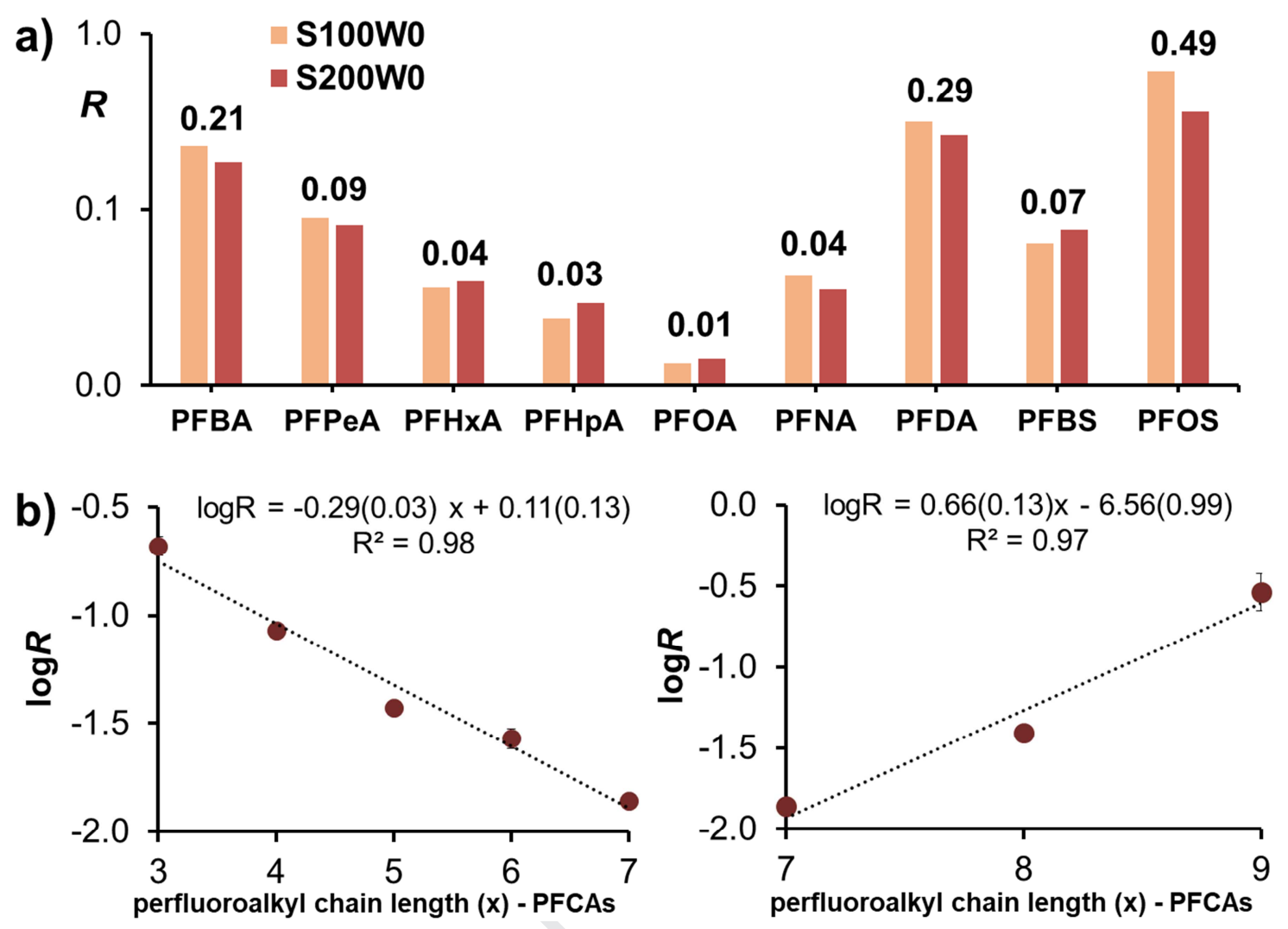

Figure 2. a) Calculated retardation factor $(R)$ values for two exposure treatments. Average $R$-values for both treatments are shown as numerical values above the bars. b) Treatment-averaged log $R$ in relation to PFCA chain length. Standard error estimates of two averaged treatments are shown as error bars.

\subsection{Partitioning}

The currently unknown link between the structure of PFAAs and their adsorption behavior requires experimental determination of sorption to soils, sediments or tissues (Droge, 2019). Measured $K_{d}$ values of short-chain PFAAs do not correlate well with the organic carbon content (\%OC) (F. Li et al., 2018; Y. Li et al., 2018; Milinovic et al., 2015; Zhu et al., 2014), and observed $K_{d}$ values for PFAAs in different soils and sediments can vary significantly (e.g. between 0.1 and $>3000 \mathrm{~L} / \mathrm{kg}$ for PFOS), underlining the need for experimental determination (F. Li et al., 2018; Y. Li et al., 2018). Nonetheless, to our knowledge, only one plant uptake study of PFAAs (apart from (Gredelj et al., 2019)) included experimental determination of the $K_{d}$ values of the growth medium (Blaine et al., 2014a, 2013). 
343 The $K_{d}$ values of PFCAs determined in these studies show a close relation to chain length, with

344 almost log-linear increase with the number of carbon atoms of perfluoroalkyl chain $\left(\mathrm{CF}_{\mathrm{x}}\right)($ Figure $3453 c$ showing the relationship from (Gredelj et al., 2019)). The $K_{d}$ values for PFCAs with less than $3466 \mathrm{CF}_{\mathrm{x}}$ are below $1 \mathrm{~L} / \mathrm{kg}$, indicating very low adsorption to soil and a significant fraction of the 347 chemical present in the soil pore water. On the contrary, $R C F_{d w}$ values are the highest for short348 chain PFCAs, being up to $260 \mathrm{~kg} / \mathrm{kg}_{\mathrm{dw}}$ (Figure 3a). Attempts to correlate the $R C F_{d w}$ to octanol349 water distribution coefficient, $\log D$ (estimated using ACD/i-Lab) were unsuccessful and are not 350 shown. Similarly, estimated adsorption to human serum albumin $K_{H S A}$ data were unsuccessful 351 for the prediction of the adsorption to roots. However, $R C F_{d w}$ shows a declining and $K_{d}$ an 352 increasing trend with the chain length (Figure $3 \mathrm{bc}$ ).

353 The combination of comparably low adsorption to soil $\left(K_{d}\right)$ and rather high partitioning into roots 354 leads to an unusually high ratio of $R C F_{d w}$ to $K_{d}$ for the short-chain PFAAs (Figure 3a). The 355 measured ratio (average of both treatments) was from $263.5 \mathrm{~kg} / \mathrm{kg}$ for PFBA to $11.4 \mathrm{~kg} / \mathrm{kg}$ for 356 PFHpA while it was lower for the long-chain PFAAs, ranging between $4.2 \mathrm{~kg} / \mathrm{kg}$ (PFOA) and 0.1 $357 \mathrm{~kg} / \mathrm{kg}$ (PFOS). For other organic compounds, the opposite has been observed, i.e. adsorption to 358 soil is typically similar or higher than adsorption to plant roots (Trapp, 1995). Usually, growth 359 dilution and loss processes within the plant lead to concentrations below equilibrium in roots, 360 and root-to-soil bioconcentration factors $<0.01 \mathrm{~kg} / \mathrm{kg}_{\mathrm{dw}}$ have been observed for lipophilic 361 compounds such as benzo(a)pyrene and PCBs (Trapp, 2002). Hence, the partitioning of PFAAs 362 (PFCAs) in the soil-root environment differs very much from that of other organic compounds.
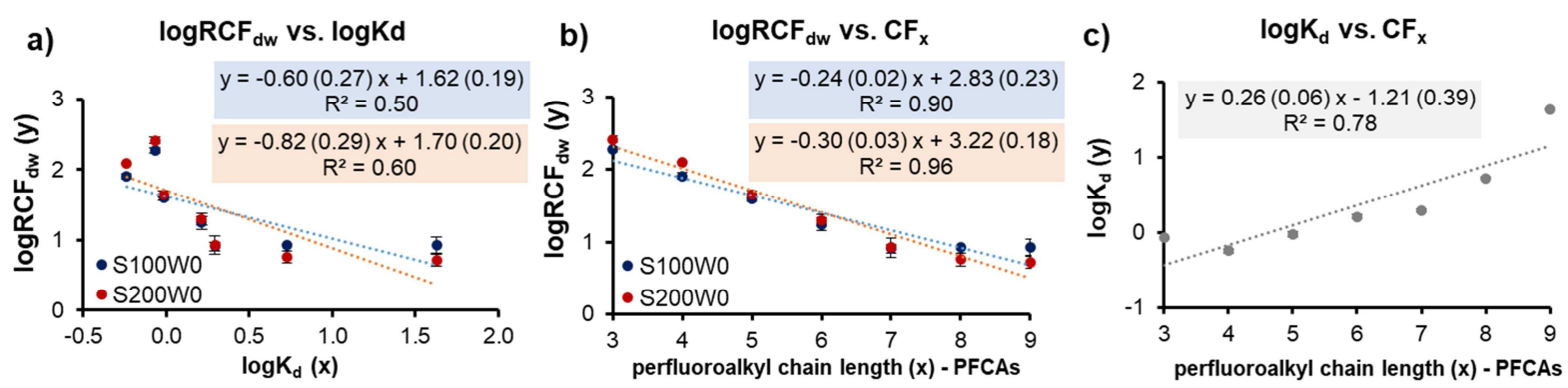
Figure 3. Regression analysis of logarithmically transformed dry weight-based root concentration factors $\left(\log R C F_{d w}\right)$, soil-water partition coefficients $\left(\log K_{d}\right)$ and PFCA chain length for red chicory (from Gredelj et al., (2019)). Standard error estimates $(\mathrm{n}=3)$ are shown for measured values of $R C F_{d w}$. Regression lines are shown with standard errors in brackets and coefficients of determination.

\subsection{Other crops}

By adapting the plant specific input data (Tables SI2 and SI5), the model can be applied to other plant species when the retardation factor $\mathrm{R}$ of each PFAA remains the same. In order to test this assumption, the approach was applied to literature crop data-sets for PFAAs (Blaine et al., 2014a, 2013). Modeled concentrations in plant compartments of tomato, celery, pea and radish are shown in Figure 4, together with the measured values. Like before, measured $R C F_{d w}$ was used to calculate $K_{R X}$ (Eq. 7). For PFAAs with high $K_{R X}$ (PFOS and PFDA), growth dilution leads to calculated root concentration somewhat below equilibrium (Table S9).

Concentration trends in shoots were estimated mostly accurately for all four crops, their values always being in the same order of a magnitude (slopes of the regression line between measured and modeled values ranging between 1.22 and 1.73), even though the $R$ values were taken from the red chicory experiments and default plant data were used (Trapp, 2015). In particular, estimations were better for the short-chain PFAAs (improving of the model evaluation statistics was noticed after elimination of long-chain PFAAs, Table S9) and for the tomato and pea $\left(R^{2}\right.$ values of 0.75 and 0.86 , respectively). For radish and celery, modeled concentrations are not far from the measured ones $\left(R^{2}\right.$ values of 0.78 and 0.52$)$, despite of their overestimation (model evaluation slopes of 1.73 and 1.32) and similar trends are shown among them (e.g., lowest concentration for PFNA). Differences between measurements and simulation results could be attributed to the use of default data instead of the carefully determined plant-specific data in the case of chicory. This hypothesis was confirmed by comparing simulation results of the red chicory experiments using measured and default plant parameters sets, whereby worse model performance was observed in the latter case, with underestimation of PFOS and PFDA in roots and shoots, and overestimation in shoots for most of the other PFAAs (see Figure S1 and 
accompanying evaluation statistics). Overestimation with the default plant data for red chicory is

392 in consistence with observations of the model performance for the other crops.

393 Simulation results for fruits typically overestimated measured data (Table S9), except for short394 chain PFAAs, and exhibited the poorest fit for PFDA and PFOS. Notably, the fruit compartment 395 is very rudimentary described in the current version of the standard plant uptake model, being 396 identical to the leaf but with reduced water flux (this is why calculated fruit concentrations follow 397 very closely the trend of the shoots, but about one order of magnitude lower). Complex 398 processes that lead to phloem loading and unloading are not adequately expressed in the 399 equations.

400

Interestingly, except for celery, $R C F_{d w}$ values of these experiments show no significant 401 correlation with the PFAA chain length (Blaine et al., 2014a) and the calibrated $R C F_{d w}$ values 402 are lower than those reported in (Gredelj et al., 2019) (Figure S2). More data for root and soil 403 concentrations are available for PFOS and PFOA than for the other PFAAs (Table S7). The 404 experimental $R C F_{d w}$ of PFOS found in literature ranged from $<0.1$ to $8.38 \mathrm{~kg} / \mathrm{kg}$, with an 405 average of $2.93 \mathrm{~kg} / \mathrm{kg}$ (Bizkarguenaga et al., 2016; Blaine et al., 2014a; Lan et al., 2018; 406 Navarro et al., 2017; Wen et al., 2016, 2014; Zhao et al., 2017) while for the red chicory 407 treatments S100W0 and S200W0 they ranged from 6.14 to $11.35 \mathrm{~kg} / \mathrm{kg}$. For PFOA, 408 experimental $R C F_{d w}$ found in literature ranged from 0.8 to $10.34 \mathrm{~kg} / \mathrm{kg}$, with average $3.3 \mathrm{~kg} / \mathrm{kg}$ 409 (Bizkarguenaga et al., 2016; Blaine et al., 2014a; Lan et al., 2018; Navarro et al., 2017; Wen et 410 al., 2016, 2014; Zhao et al., 2017) while the range for red chicory was from 8.10 to $10.31 \mathrm{~kg} / \mathrm{kg}$. 

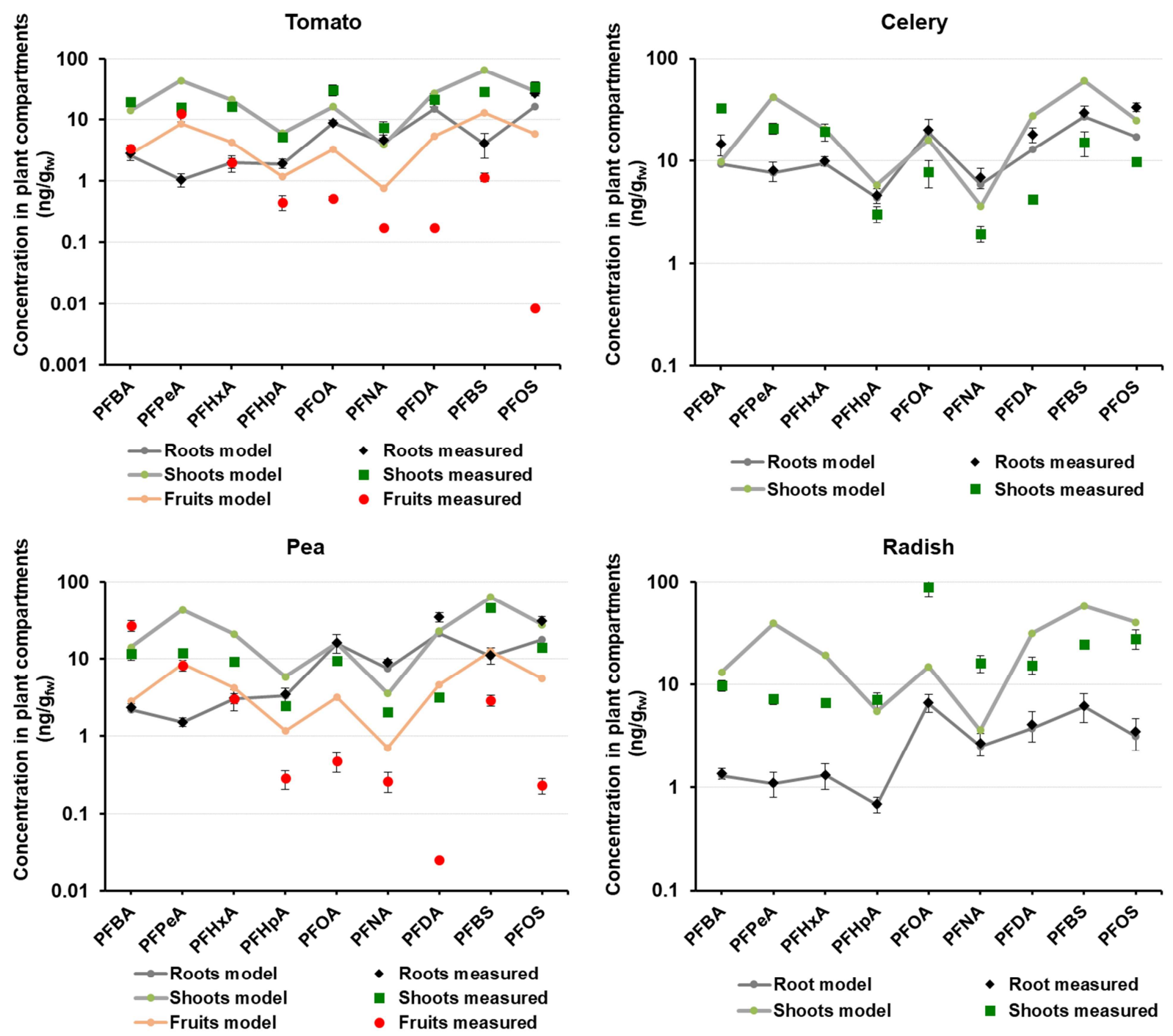

Figure 4. Comparison of modeled and measured PFAA concentrations in crops. Measured values are shown as means with standard errors and are taken from (Blaine et al., 2014a, 2013).

\section{4. Conclusions}

415 "Mathematical models provide a framework for understanding the cycling of compounds through

416 environment" (Ramaswami et al., 2005). We thus applied a plant uptake model to interpret 417 measured plant uptake data for PFAAs and gained new insights in uptake processes and 418 accumulation mechanisms. 
The high concentrations of perfluoroalkyl acids (and in particular short-chain PFAAs) in crops are neither due to rapid plant uptake, nor due to active or preferential transport, nor due to exceptionally high adsorption to plant material. We found two main reasons for the observed high accumulation potential of PFAAs in terrestrial crop plants:

i) Partition coefficients. The root-to-xylem partition coefficients $K_{R X}$, here derived from measured $R C F_{d w}$, ranged from $<1$ to $54 \mathrm{~L} / \mathrm{kg}_{\mathrm{fw}}$. The highest values were observed for the shortest PFAA $\left(3 \mathrm{CF}_{x}, \mathrm{PFBA}\right), \mathrm{PFDA}$ and PFOS. At the same time, $K_{d}$ values (expressing adsorption to soil) of the short-chain PFAAs are small, $<1 \mathrm{~L} / \mathrm{kg}$. Thus, these PFAAs show very high bioavailability in soil and rapid transport with water. The combination of low $K_{d}$ and relatively high $K_{R X}$ (or $R C F_{d w}$ ) is rather unusual and has not been described before. The accumulation of chemicals in roots is determined by the ratio $K_{\mathrm{RX}} / K_{\mathrm{d}}$, and this leads to the observed very high concentrations of short-chain PFAAs in chicory roots and consequently leaves and head. For PFOA, PFNA, PFDA and PFOS, $K_{d}$ is higher than $R C F_{d w}$, and less accumulation in roots and shoots was accordingly observed.

ii) System dynamics. PFAAs show no rapid uptake into roots. Possibly due to their unusual chemical properties (being hydrophobic and lipophobic at the same time), their biomembrane permeability is slow, in any case slower than that of water $(R<1)$, and the retardation factor appears to be independent of the type of crop. Slow transport across biomembranes is typical 437 for very polar or highly charged compounds. However, there are no loss processes of relevance 438 known within the plant. Neither biotic nor abiotic degradation nor volatilization lead to a decline 439 of chemical mass once the chemical has been taken up. The permanent transport to and within 440 the plant with the transpiration water over time leads to very high concentrations, and no steady441 state is reached. This is the best seen from the solution of the underlying differential equation, $442 m(t)=I / k\left(1-e^{-k t}\right)$, where $m(t)$ is the mass in plant shoots at time $t, I$ is the input (here with the transpiration water) and $k$ is the sum of loss processes. With very small loss $\left(k\right.$ close to $\left.0 \mathrm{~d}^{-1}\right)$, 
444 chemical mass in the shoots increases steadily as long as the chemical is transported into plant 445 and shoots with the water taken up. Thus, considerable accumulation can be reached with 446 longer time periods provided that the input of chemical is constant (a reasonable assumption for 447 long-term contamination events, such as the one in the Veneto Region, Italy).

448 Having in mind (a) the strong affinity of PFAAs (particularly short-chain) for crop uptake through 449 roots, (b) the long maturation period of some crops, (c) crop-dependent uptake and particularly 450 (d) soil-type dependency as the only way for decreasing the bioavailability of PFAAs to roots 451 through the soil sorption, research is urgently needed to improve the mechanistic understanding 452 and allow predicting PFAAs uptake in crops, eventually leading towards more reliable human 453 health exposure and risk assessment for these substances.

\section{Acknowledgements}

456 Andrea Gredelj's PhD research was funded by the Fondazione CARIPARO's grant for foreign 457 PhD students at the University of Padova. 


\section{References}

459

460

461

462

463

464

465

466

467

468

469

470

471

472

473

474

475

476

477

478

479

480

481

482

483

484

485

486

487

488

489

490

491

492

493

494

495

496

497

498

499

ASTM International, 2019. ASTM D2216, Standard Test Methods for Laboratory Determination of Water (Moisture) Content of Soil and Rock by Mass. West Conshohocken, PA. https://doi.org/10.1520/D2216-19

Bizkarguenaga, E., Zabaleta, I., Mijangos, L., Iparraguirre, A., Fernández, L.A., Prieto, A., Zuloaga, O., 2016. Uptake of perfluorooctanoic acid, perfluorooctane sulfonate and perfluorooctane sulfonamide by carrot and lettuce from compost amended soil. Sci. Total Environ. https://doi.org/10.1016/j.scitotenv.2016.07.010

Blaine, A.C., Rich, C.D., Hundal, L.S., Lau, C., Mills, M.A., Harris, K.M., Higgins, C.P., 2013. Uptake of perfluoroalkyl acids into edible crops via land applied biosolids: Field and greenhouse studies. Environ. Sci. Technol. 47, 14062-14069. https://doi.org/10.1021/es403094q

Blaine, A.C., Rich, C.D., Sedlacko, E.M., Hundal, L.S., Kumar, K., Lau, C., Mills, M.A., Harris, K.M., Higgins, C.P., 2014a. Perfluoroalkyl acid distribution in various plant compartments of edible crops grown in biosolids-amended soils. Environ. Sci. Technol. 48, 7858-7865. https://doi.org/10.1021/es500016s

Blaine, A.C., Rich, C.D., Sedlacko, E.M., Hyland, K.C., Stushnoff, C., Dickenson, E.R. V., Higgins, C.P., 2014b. Perfluoroalkyl Acid Uptake in Lettuce (Lactuca sativa) and Strawberry (Fragaria ananassa) Irrigated with Reclaimed Water. Environ. Sci. Technol. 48, 14361-14368. https://doi.org/10.1021/es504150h

Brand, E., Otte, P.F., Lijzen, J.P.A., 2007. CSOIL 2000: an exposure model for human risk assessment of soil contamination. Bilthoven (NL).

Brendel, S., Fetter, É., Staude, C., Vierke, L., Biegel-Engler, A., 2018. Short-chain perfluoroalkyl acids: environmental concerns and a regulatory strategy under REACH. Environ. Sci. Eur. 30, 9. https://doi.org/10.1186/s12302-018-0134-4

Briggs, G.G., Bromilow, R.H., Evans, A.A., 1982. Relationships between lipophilicity and root uptake and translocation of non-ionised chemicals by barley. Pestic. Sci. 13, 495-504. https://doi.org/10.1002/ps.2780130506

Briggs, G.G., Rigitano, R.L.O., Bromilow, R.H., 1987. Physico-chemical factors affecting uptake by roots and translocation to shoots of weak acids in barley. Pestic. Sci. 19, 101-112. https://doi.org/10.1002/ps.2780190203

Buck, R.C., Franklin, J., Berger, U., Conder, J.M., Cousins, I.T., de Voogt, P., Jensen, A.A., Kannan, K., Mabury, S.A., van Leeuwen, S.P., 2011. Perfluoroalkyl and polyfluoroalkyl substances in the environment: Terminology, classification, and origins. Integr. Environ. Assess. Manag. 7, 513-541. https://doi.org/10.1002/ieam.258

Chen, H., Reinhard, M., Nguyen, T.V., You, L., He, Y., Gin, K.Y.H., 2017. Characterization of occurrence, sources and sinks of perfluoroalkyl and polyfluoroalkyl substances (PFASs) in a tropical urban catchment. Environ. Pollut. 227, 397-405. https://doi.org/10.1016/j.envpol.2017.04.091

Chen, H., Reinhard, M., Nguyen, V.T., Gin, K.Y.H., 2016. Reversible and irreversible sorption of perfluorinated compounds (PFCs) by sediments of an urban reservoir. Chemosphere 144, 1747-1753. https://doi.org/10.1016/j.chemosphere.2015.10.055 
Cheng, W., Ng, C.A., 2018. Predicting Relative Protein Affinity of Novel Per- and Polyfluoroalkyl Substances (PFASs) by An Efficient Molecular Dynamics Approach. Environ. Sci. Technol. 52, 7972-7980. https://doi.org/10.1021/acs.est.8b01268

D'Hollander, W., Herzke, D., Huber, S., Hajslova, J., Pulkrabova, J., Brambilla, G., De Filippis, S.P., Bervoets, L., de Voogt, P., 2015. Occurrence of perfluorinated alkylated substances in cereals, salt, sweets and fruit items collected in four European countries. Chemosphere 129, 179-185. https://doi.org/10.1016/j.chemosphere.2014.10.011

Dettenmaier, E.M., Doucette, W.J., Bugbee, B., 2009. Chemical hydrophobicity and uptake by plant roots. Environ. Sci. Technol. 43, 324-329. https://doi.org/10.1021/es801751x

DeWitt, J., Berger, U., Miller, M., Green, C., Huang, J., Perkola, N., Vierke, L., Higgins, C., Buser, A.M., Lindstrom, A.B., Boucher, J.M., Lau, C.S., Knepper, T., Liu, J., Wang, Z., Herzke, D., Ahrens, L., Hung, H., Cousins, I., van der Jagt, K., Bopp, S.K., Fletcher, T., Leinala, E., Scheringer, M., Småstuen Haug, L., Borg, D., Ritscher, A., Valsecchi, S., Shi, Y., Ohno, K., Trier, X., Bintein, S., 2018. Zürich Statement on Future Actions on Per- and Polyfluoroalkyl Substances (PFASs). Environ. Health Perspect. 126, 084502. https://doi.org/10.1289/ehp4158

Droge, S.T.J., 2019. Membrane-Water Partition Coefficients to Aid Risk Assessment of Perfluoroalkyl Anions and Alkyl Sulfates. Environ. Sci. Technol. 53, 760-770. https://doi.org/10.1021/acs.est.8b05052

European Commission, 2003. Technical Guidance Document on Risk Assessment in support of Commission Directive 93/67/EEC on Risk Assessment for new notified substances, Commission Regulation (EC) No 1488/94 on Risk Assessment for existing substances, and Directive 98/8/EC of the Euro. Ispra.

Fantke, P., Charles, R., Alencastro, L.F. de, Friedrich, R., Jolliet, O., 2011a. Plant uptake of pesticides and human health: Dynamic modeling of residues in wheat and ingestion intake. Chemosphere 85, 1639-1647. https://doi.org/10.1016/j.chemosphere.2011.08.030

Fantke, P., Juraske, R., Antón, A., Friedrich, R., Jolliet, O., 2011b. Dynamic multicrop model to characterize impacts of pesticides in food. Environ. Sci. Technol. 45, 8842-8849. https://doi.org/10.1021/es201989d

Felizeter, S., McLachlan, M.S., De Voogt, P., 2014. Root uptake and translocation of perfluorinated alkyl acids by three hydroponically grown crops. J. Agric. Food Chem. 62, 3334-3342. https://doi.org/10.1021/jf500674j

Felizeter, S., McLachlan, M.S., De Voogt, P., 2012. Uptake of perfluorinated alkyl acids by hydroponically grown lettuce (Lactuca sativa). Environ. Sci. Technol. 46, 11735-11743. https://doi.org/10.1021/es302398u

Franco, A., Fu, W., Trapp, S., 2009. Influence of soil pH on the sorption of ionizable chemicals: Modeling advances. Environ. Toxicol. Chem. 28, 458-464. https://doi.org/10.1897/08-178.1

Ghisi, R., Vamerali, T., Manzetti, S., 2019. Accumulation of perfluorinated alkyl substances (PFAS) in agricultural plants: A review. Environ. Res. 169, 326-341. https://doi.org/10.1016/j.envres.2018.10.023

Gourlay, V., 2017. Development and application of hydroponic test systems for the determination of plant uptake factors (PUF) of xenobiotics to be used as parameters in environmental fate models. Shaker Verlag GmbH, Germany, Aachen. 
Greaves, A.K., Letcher, R.J., Sonne, C., Dietz, R., Born, E.W., 2012. Tissue-Specific Concentrations and Patterns of Perfluoroalkyl Carboxylates and Sulfonates in East Greenland Polar Bears. Environ. Sci. Technol. 46, 11575-11583. https://doi.org/10.1021/es303400f

Gredelj, A., Nicoletto, C., Valsecchi, S., Ferrario, C., Polesello, S., Lava, R., Zanon, F., Barausse, A., Palmeri, L., Guidolin, L., Bonato, M., 2019. Uptake and translocation of perfluoroalkyl acids (PFAA) in red chicory (Cichorium intybus L.) under various treatments with pre-contaminated soil and irrigation water. Sci. Total Environ. https://doi.org/10.1016/j.scitotenv.2019.134766

Guelfo, J.L., Higgins, C.P., 2013. Subsurface transport potential of perfluoroalkyl acids at aqueous film-forming foam (AFFF)-impacted sites. Environ. Sci. Technol. 47, 4164-4171. https://doi.org/10.1021/es3048043

Jeffries, J., Martin, I., 2009. Updated technical background to the CLEA model. Almondsbury (UK).

Klenow, S., Heinemeyer, G., Brambilla, G., Dellatte, E., Herzke, D., de Voogt, P., 2013. Dietary exposure to selected perfluoroalkyl acids (PFAAs) in four European regions. Food Addit. Contam. - Part A Chem. Anal. Control. Expo. Risk Assess. 30, 2141-2151. https://doi.org/10.1080/19440049.2013.849006

Krafft, M.P., Riess, J.G., 2015. Per- and polyfluorinated substances (PFASs): Environmental challenges. Curr. Opin. Colloid Interface Sci. 20, 192-212. https://doi.org/10.1016/j.cocis.2015.07.004

Lamshoeft, M., Gao, Z., Resseler, H., Schriever, C., Sur, R., Sweeney, P., Webb, S., Zillgens, B., Reitz, M.U., 2018. Evaluation of a novel test design to determine uptake of chemicals by plant roots. Sci. Total Environ. 613-614, 10-19. https://doi.org/10.1016/j.scitotenv.2017.08.314

Lan, Z., Zhou, M., Yao, Y., Sun, H., 2018. Plant uptake and translocation of perfluoroalkyl acids in a wheat-soil system. Environ. Sci. Pollut. Res. 25, 30907-30916. https://doi.org/10.1007/s11356-018-3070-3

Legind, C.N., Trapp, S., 2009. Modeling the exposure of children and adults via diet to chemicals in the environment with crop-specific models. Environ. Pollut. 157, 778-785. https://doi.org/10.1016/j.envpol.2008.11.021

Li, F., Fang, X., Zhou, Z., Liao, X., Zou, J., Yuan, B., Sun, W., 2018. Adsorption of perfluorinated acids onto soils: Kinetics, isotherms, and influences of soil properties. Sci. Total Environ. 649, 504-514. https://doi.org/https://doi.org/10.1016/j.scitotenv.2018.08.209

Li, Y., Oliver, D.P., Kookana, R.S., 2018. A critical analysis of published data to discern the role of soil and sediment properties in determining sorption of per and polyfluoroalkyl substances (PFASs). Sci. Total Environ. 628-629, 110-120. https://doi.org/10.1016/j.scitotenv.2018.01.167

Liu, J., Mejia Avendaño, S., 2013. Microbial degradation of polyfluoroalkyl chemicals in the environment: A review. Environ. Int. 61, 98-114. https://doi.org/10.1016/j.envint.2013.08.022

Mc Farlane, C., Trapp, S., 1994. Plant Contamination: Modeling and Simulation of Organic Chemical Processes, 1st ed. CRC Press, Boca Raton, Florida. 
603

604

605

606

607 608

609

610

611

612

613

614

615

616

617

618

619

620

621

622

623

624

625

626

McLachlan, M.S., Felizeter, S., Klein, M., Kotthoff, M., De Voogt, P., 2019. Fate of a perfluoroalkyl acid mixture in an agricultural soil studied in lysimeters. Chemosphere 223, 180-187. https://doi.org/10.1016/j.chemosphere.2019.02.012

Milinovic, J., Lacorte, S., Vidal, M., Rigol, A., 2015. Sorption behaviour of perfluoroalkyl substances in soils. Sci. Total Environ. 511, 63-71. https://doi.org/10.1016/j.scitotenv.2014.12.017

Navarro, I., de la Torre, A., Sanz, P., Porcel, M.Á., Pro, J., Carbonell, G., Martínez, M. de los Á., 2017. Uptake of perfluoroalkyl substances and halogenated flame retardants by crop plants grown in biosolids-amended soils. Environ. Res. 152, 199-206. https://doi.org/10.1016/j.envres.2016.10.018

$\mathrm{Ng}$, C.A., Hungerbühler, K., 2014. Bioaccumulation of perfluorinated alkyl acids: Observations and models. Environ. Sci. Technol. 48, 4637-4648. https://doi.org/10.1021/es404008g

OECD, 2000. Test No. 106: Adsorption - Desorption Using a Batch Equilibrium Method, OECD Guideline for the Testing of Chemicals. https://doi.org/https://doi.org/10.1787/9789264069602-en

Ramaswami, A., Milford, J.B., Small, M.J., 2005. Integrated Environmental Modeling: Pollutant Transport, Fate, and Risk in the Environment. John Wiley and Sons, Hoboken, New Jersey.

Smith, J.W.N., Beuthe, B., Dunk, M., Demeure, S., Carmona, J.M.M., Medve, A., Spence, M.J., Pancras, T., Schrauwen, G., Held, T., Baker, K., Ross, I., Slenders, H., 2016. Environmental fate and effects of poly- and perfluoroalkyl substances (PFAS). Brussels.

Steudle, E., Peterson, C.A., 1998. How does water get through roots? J. Exp. Bot. 49, 775-788. https://doi.org/10.1093/jexbot/49.322.775

Trapp, S., 2015. Calibration of a plant uptake model with plant- and site-specific data for uptake of chlorinated organic compounds into radish. Environ. Sci. Technol. 49, 395-402. https://doi.org/10.1021/es503437p

Trapp, S., 2009. Bioaccumulation of Polar and lonizable Compounds in Plants, in: Devillers, J. (Ed.), Ecotoxicology Modeling, Emerging Topics in Ecotoxicology: Principles, Approaches and Perspectives 2. Springer US, Rillieux La Pape, p. 400. https://doi.org/10.1007/978-14419-0197-2

Trapp, S., 2007. Fruit tree model for uptake of organic compounds from soil and air. SAR QSAR Environ. Res. 18, 367-387. https://doi.org/10.1080/10629360701303693

Trapp, S., 2004. Plant Uptake and Transport Models for Neutral and Ionic Chemicals. Environ. Sci. Pollut. Res. 11, 33-39. https://doi.org/10.1065/espr2003.08.169

Trapp, S., 2002. Dynamic root uptake model for neutral lipophilic organics. Environ. Toxicol. Chem. 21, 203-206. https://doi.org/10.1002/etc.5620210128

Trapp, S., 1995. Model for Uptake of Xenobiotics into Plants., in: Trapp, S., McFarlane, J.C. (Eds.), Plant Contamination: Modeling and Simulation of Organic Chemical Processes. Lewis Publishers, Boca Raton, pp. 107-152.

Trapp, S., Franco, A., MacKay, D., 2010. Activity-based concept for transport and partitioning of ionizing organics. Environ. Sci. Technol. 44, 6123-6129. https://doi.org/10.1021/es100509x 
Trapp, S., Matthies, M., 1995. Generic One-Compartment Model for Uptake of Organic Chemicals by Foliar Vegetation. Environ. Sci. Technol. 29, 2333-2338. https://doi.org/10.1021/es00009a027

Veneto Region, 2014. Progress and prospects for Veneto Agriculture. [http://statistica.regione.veneto.it/ENG/Pubblicazioni/RapportoStatistico2014/pdf/Capitolo07 .pdf]

Wen, B., Li, L., Zhang, H., Ma, Y., Shan, X.Q., Zhang, S., 2014. Field study on the uptake and translocation of perfluoroalkyl acids (PFAAs) by wheat (Triticum aestivum L.) grown in biosolids-amended soils. Environ. Pollut. 184, 547-554. https://doi.org/10.1016/j.envpol.2013.09.040

Wen, B., Wu, Y., Zhang, H., Liu, Y., Hu, X., Huang, H., Zhang, S., 2016. The roles of protein and lipid in the accumulation and distribution of perfluorooctane sulfonate (PFOS) and perfluorooctanoate (PFOA) in plants grown in biosolids-amended soils. Environ. Pollut. 216, 682-688. https://doi.org/10.1016/j.envpol.2016.06.032

WHO, 2016. Keeping our water clean: the case of water contamination in the Veneto Region, Italy. AREAGRAPHICA SNC DI TREVISAN GIANCARLO \& FIGLI, Venice, Italy.

[http://www.euro.who.int/_data/assets/pdf_file/0018/340704/FINAL_pfas-report-20170530h1200.pdf]

Xiang, L., Chen, L., Yu, L.-Y., Yu, P.-F., Zhao, H.-M., Mo, C.-H., Li, Y.-W., Li, H., Cai, Q.-Y., Zhou, D.-M., Wong, M.-H., 2018. Genotypic variation and mechanism in uptake and translocation of perfluorooctanoic acid (PFOA) in lettuce (Lactuca sativa L.) cultivars grown in PFOA-polluted soils. Sci. Total Environ. https://doi.org/10.1016/j.scitotenv.2018.04.354

Zhao, S., Fan, Z., Sun, L., Zhou, T., Xing, Y., Liu, L., 2017. Interaction effects on uptake and toxicity of perfluoroalkyl substances and cadmium in wheat (Triticum aestivum L.) and rapeseed (Brassica campestris L.) from co-contaminated soil. Ecotoxicol. Environ. Saf. 137, 194-201. https://doi.org/10.1016/j.ecoenv.2016.12.007

Zhu, Z., Wang, T., Wang, P., Lu, Y., Giesy, J.P., 2014. Perfluoroalkyl and polyfluoroalkyl substances in sediments from South Bohai coastal watersheds, China. Mar. Pollut. Bull. 85, 619-627. https://doi.org/10.1016/j.marpolbul.2013.12.042 


\section{Highlights:}

- Short-chain perfluoroalkyl acids (PFAAs) are highly bioaccumulative in edible crops

- Plant uptake model extended to interpret the uptake of nine PFAAs into red chicory

- New parameter $R$ for slow transfer through root membranes estimated for red chicory

- The newly developed semi-empirical model was successfully applied for other crops

- High PFAA uptake in plants is the combination of persistence, low $\mathrm{K}_{\mathrm{d}}$ and high RCF 


\section{Declaration of interests}

$\bigotimes$ The authors declare that they have no known competing financial interests or personal relationships that could have appeared to influence the work reported in this paper.

$\square$ The authors declare the following financial interests/personal relationships which may be considered as potential competing interests: 